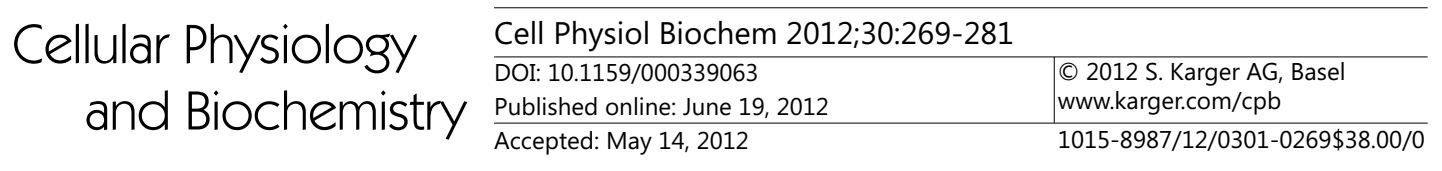

\title{
Regulation of Organic Cation Transport in Isolated Mouse Proximal Tubules Involves Complex Changes in Protein Trafficking and Substrate Affinity
}

\author{
Denise Guckel Giuliano Ciarimboli Hermann Pavenstädt Eberhard Schlatter
}

Medizinische Klinik und Poliklinik D, Experimentelle Nephrologie, Universität Münster

\section{Key Words}

Organic cation transport • Protein kinases • Trafficking • Substrate affinities • Proximal tubule - Microfluorimetry

\begin{abstract}
This study characterizes the complex mechanisms of acute regulation of organic cation (OC) transport across the basolateral membrane of isolated mouse proximal tubules. The fluorescent substrate $\mathrm{ASP}^{+}, 4-(-4-$ (dimethylamino) styryl-N-methylpyridinium, was used to quantify $O C$ transport using a microtiter plate based fluorescence reader method. Inhibition of phosphatidylinositol-3-kinase, of p56 tyrosine kinase, stimulation of PKC and inhibition of PKA reduced $\mathrm{ASP}^{+}$-uptake. $\mathrm{ASP}^{+}$-kinetic and Dixon plot analyses revealed effects on transporter trafficking as explanation for the inhibition of $\mathrm{ASP}^{+}$-uptake by these pathways. Angiotensin II (AII) via stimulation of $\mathrm{Ca}^{2+} /$ calmodulin increased $\mathrm{ASP}^{+}$-uptake. This effect aroused from an altered substrate affinity. Bafilomycin, an inhibitor of the vacuolar $\mathrm{H}^{+}$-ATPase and thus endosomal and lysosomal function, reduced $\mathrm{ASP}^{+}$-uptake, but did not prevent the AII effect on $\mathrm{ASP}^{+}$-uptake. Bafilomycin seemed to diminish the recycling rate of OCTs and hence to reduce the amount of transporters in the membrane. AII via $\mathrm{Ca}^{2+} / \mathrm{calmodulin}$ increased the substrate affinity of the remaining OCTs. The involvement of the cytoskeleton in acute regulation of OCTs became obvious as colchicine induced inhibition of microtubule polymerisation reduced $\mathrm{ASP}^{+}$-uptake. Acute regulation of mouse OCTs mostly involves changes in trafficking from and to the plasma membrane and only in the case of AII/CaM changes in substrate affinity.
\end{abstract}

Copyright (C 2012 S. Karger AG, Basel 


\section{Cellular Physiology Cell Physiol Biochem 2012:30:269-281

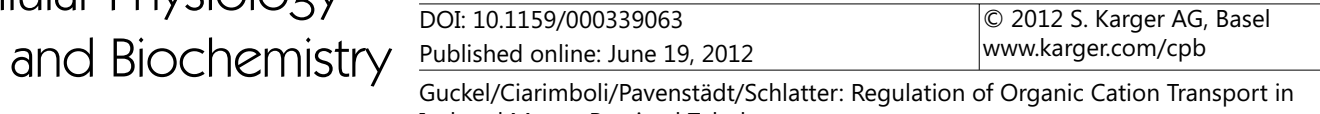 \\ Guckel/Ciarimboli/Pavenstädt/Sc
Isolated Mouse Proximal Tubules}

\section{Introduction}

Organic cation transporters (OCTs) are membrane proteins, which translocate organic cations (OCs) across the plasma membrane. In mammals the proximal tubule (PT) serves as the main renal elimination site of endogenous (e.g. choline, dopamine) and exogenous (e.g. cimetidine, procainamide, quinine and vecuronium) OCs [1,2]. For this reason, OCTs have important physiological, pharmacological, toxicological and clinical implications. Specifically, their great importance becomes obvious by e.g. taking into account their pivotal role in the elimination of environmental toxins [3] and in reducing the exposure of the body to specific drug toxicities [4] such as antibiotics, antihistamines [5], cytostatics [6-9] or antiarrhythmics [10]. However, OCTs are also involved in toxic side effects of such compounds as they can lead to specific cellular accumulation [6-9, 11]. In the long run the targeted modulation of their activity by diverse inhibitors or protein kinases could e.g. reduce toxic side effects and improve treatment efficacy instead. But first of all further detailed inside into the intracellular signalling cascades, which acutely affect $\mathrm{OC}$ transport, has to be provided. OC transport has been characterized as bidirectional $[12,13]$, polyspecific [14] and electrogenic $[12,13,15-17]$, but $\mathrm{pH}-$ and $\mathrm{Na}^{+}$independent $[12,13,15]$. Three different isoforms have been identified each in rat, mouse and man (OCT1, OCT2 and OCT3). All of them belong to the solute carrier 22A superfamily (SLC22A) [14]. They physiologically occur predominantly in intestine, liver, brain and kidney [4, 17-19]. However, the expression and distribution of these isoforms differ in dependence of species and organs [14]. In rat PTs OCT1, which was the first OCT to be cloned, and OCT2 are highly expressed in parallel [16] whereas in human kidneys OCT2 is the predominant isoform [15]. In mouse kidney OCT1 and OCT2 are the dominant isoforms on mRNA level, while OCT3 shows only very minor expression [20]. The molecular structure of OCTs consists of twelve alpha helical transmembrane domains (TMDs) with a large hydrophilic extracellular loop between the first and second TMD and a large intracellular loop between the sixth and seventh TMD. Especially the intracellular domain and the c-terminal end contain several potential phosphorylation sites [2, 21], which are targets for protein kinases. So far several pathways have been identified which acutely regulate OCTs, mostly without identifying the involved mechanisms of molecular interaction. Although transgenic mouse models are commonly used for e.g. translational research, the functional properties, particularly detailed mechanisms of short-term regulation of OCTs in the mouse, are not yet sufficiently examined and described. This is especially true for the in/ ex vivo situation. Therefore this study aims to characterize the complex pattern underlying mechanisms of acute regulation of OC transport across the basolateral membrane of freshly isolated mouse PTs focussing on protein kinase dependent signalling pathways and kinetic analyses. Moreover, we put emphasis on the role of cellular protein degradation and the involvement of essential components of the cytoskeleton, e.g. microtubules, in these regulatory mechanisms. Due to the fact that PTs express OCT1, OCT2 and to a minor extent also OCT3 all data presented in this study reflect the sum of effects on all three isoforms as present in the in vivo situation.

\section{Materials and Methods}

\section{Animals}

Nine week-old male C57BL/6 mice ( $n=65$, Charles River, Sulzfeld, Germany) were kept under temperature-, light- and humidity-controlled conditions and had free access to water and standard mice chow (Sniff, Soest, Germany). Experiments were approved by a governmental committee on animal welfare and were performed in accordance with national animal protection laws (06705.2011.256, LANUV NRW Recklinghausen, Germany). 


\section{Cellular Physiolosy Cell Physiol Biochem 2012;30:269-281 \\ \begin{tabular}{ll|l} 
and BiOChemistry & $\begin{array}{l}\text { DOI: 10.1159/000339063 } \\
\text { Published online: June 19, } 2012\end{array}$ & $\begin{array}{l}\text { C } 2012 \text { S. Karger AG, Basel } \\
\text { www.karger.com/cpb }\end{array}$ \\
$\begin{array}{l}\text { Guckel/Ciarimboli/Pavenstädt/Schlatter: Regulation of Organic Cation Transport in } \\
\text { Isolated Mouse Proximal Tubules }\end{array}$
\end{tabular}}

Isolation of tubular segments and experimental solutions

In most cases, up to 800 PTs (S2 and S3 segments) were mechanically isolated by two experimenters from one or both kidneys of a mouse within 2 hours after nephrectomy. Experiments were performed within the next 2-4 hours as previous experiments validated that the specificity of $\mathrm{ASP}^{+}$-uptake remains stable at least up to 4 hours after tubule isolation [20]. During the dissection under the microscope tubules were kept in MEM-EARLE medium (Biochrom, Berlin, Germany) at $4^{\circ} \mathrm{C}$ and later transferred to $\mathrm{HCO}_{3}$-free Ringer-like control solution containing (in mM): $\mathrm{NaCl} 145, \mathrm{~K}_{2} \mathrm{HPO}_{4} 1.6, \mathrm{KH}_{2} \mathrm{PO}_{4} 0.4$, D-glucose $5, \mathrm{MgCl}_{2} 1$, calcium gluconate 1.3 , and $\mathrm{pH}$ adjusted to 7.4. Afterwards three tubule segments (total length approximately $500 \mu \mathrm{m}$ ) were transferred into one well of a 384 well microtiter plate (Deep Well Small Volume, Greiner, Frickenhausen, Germany) with $10 \mu \mathrm{l}$ of control solution. To remove air bubbles in the wells which could disturb the measurements and to make the tubules gently settle down at the bottom of the wells the microtiter plate was mildly centrifuged for $10 \mathrm{~min}$ before starting the experiments. For regulatory experiments PTs were incubated with another $10 \mu \mathrm{l}$ of control solution containing the respective agonists or antagonists at $37^{\circ} \mathrm{C}$. These agonists and antagonists were present throughout the whole experiment. For all other measurements $10 \mu \mathrm{l}$ of control solution were added to each well. In all experiments $5 \mu \mathrm{l} \mathrm{ASP} \mathrm{P}^{+}$dissolved in control solution were injected by the fluorescence reader to achieve a final concentration of $1 \mu \mathrm{M}$ (except indicated differently). In addition competitive organic cations were added to this $\mathrm{ASP}^{+}$-solution.

\section{Fluorescence measurements}

As customary in our laboratory $\mathrm{ASP}^{+}, 4$-(4-(dimethylamino)styryl-N-methyl-pyridinium, a positively charged fluorescent dye $[17,21,22]$, served as substrate in order to quantify OC transport across the basolateral membrane of isolated PTs. Microfluometric measurements were exerted with a fluorescence plate reader (Infinity M200, Tecan, Crailsheim, Germany) (excitation at $465 \pm 35 \mathrm{~nm}$, emission at $590 \pm 20$ $\mathrm{nm}$ ) at $37^{\circ} \mathrm{C}$ to semi-automatically analyse OC transport [20]. Fluorescence was measured dynamically in each well before and after $\mathrm{ASP}^{+}$-injection and plotted versus time. $\mathrm{ASP}^{+}$and other organic cations were added after the third sampling interval. Emission from the complete area of the well bottom was analysed four times and averaged for each well. After being taken up by the cell $\mathrm{ASP}^{+}$shows a shift in its emission spectrum [23]. Therefore the initial linear fluorescence increase, measured by linear regression within the first 100 seconds, visualizes the specific cellular uptake of $\mathrm{ASP}^{+}$across plasma membranes and is not significantly influenced by transport of $\mathrm{ASP}^{+}$out of the cells, intracellular compartmentalization and bleaching of the dye $[17,22,24]$. Background fluorescence was measured for each plate in wells with identical solutions but no tubules and subtracted from each well containing tubules. Experiments were performed with tubules isolated from one animal per day with controls and test substances in the same plate.

\section{Chemicals}

Tetrapentylammonium $\left(\mathrm{TPA}^{+}\right)$, cimetidine, human angiotensin II, bafilomycin, sn-1,2-dioctanoyl glycerol and colchicine were purchased from Sigma. Calmidazolium, aminogenistein, wortmannin, KT5720, calphostin C and EGF were obtained from Calbiochem (Bad Soden, Germany), insulin from Novo Nordisk (Mainz, Germany), IGF-1 from Roche Molecular Biochemicals (Basel, Switzerland) and IL-1 $\alpha$ from R\&D (Minneapolis, Minnesota, USA). ASP ${ }^{+}$was purchased from Molecular Probes/Invitrogen, Karlsruhe, Germany. All other substances and standard chemicals were obtained from Sigma or Merck (Darmstadt, Germany). Compounds were dissolved in $\mathrm{HCO}_{3}$ - free Ringer-like solution (see above) and if necessary with ethanol or dimethylsulphoxide (DMSO) as solvent. The final concentration of these solvents did not affect the results of the experiments (data not shown).

\section{Statistical analyses}

Data are presented as mean values \pm SEM, with (n) referring to the number of wells. $\mathrm{K}_{\mathrm{m}}-$ and $\mathrm{V}_{\max }$ - values were obtained by sigmoidal concentration-response curve fitting or by Dixon plot analyses using GraphPad Prism, Version 5.3 (GraphPad Software, San Diego, USA). Unpaired two-sided Student's t-test was employed to prove statistical significance of the effects. For multiple comparisons ANOVA with Bonferroni post-test was used. A $P$-value $<0.05$ was considered statistically significant.

\section{Results}

\section{ASP'-transport}

Cellular $\mathrm{ASP}^{+}$-accumulation across the basolateral membrane of PTs is concentration dependent and shows an OCT- and transporter-independent component. The mOCT specific 


\section{Cellular Physiology \\ Cell Physiol Biochem 2012;30:269-281 \\ and Biochemistry

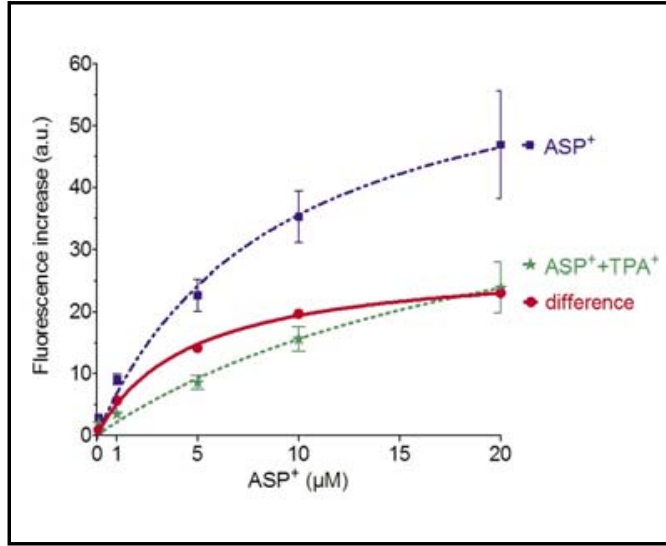

Fig. 1. Kinetics of $\mathrm{ASP}^{+}$-uptake. mOCT-dependent initial $\mathrm{ASP}^{+}$-uptake rates (continuous line, difference) were obtained by subtraction of the mOCT-independent $\mathrm{ASP}^{+}$-uptake in the presence of $\mathrm{TPA}^{+}(3 \mathrm{mM})$ (dashed line, $\mathrm{ASP}^{+}+\mathrm{TPA}^{+}$) from the total uptake (dashed line, $\mathrm{ASP}^{+}$). Data are given as mean values \pm SEM, with 64 to 103 observations at each data point. From this mOCT-dependent curve (difference) a $\mathrm{k}_{\mathrm{m}}$ of $4.6 \pm 0.5 \mu \mathrm{M}$ and a $\mathrm{V}_{\max }$ of 28.3 \pm 1.0 a.u. were calculated.

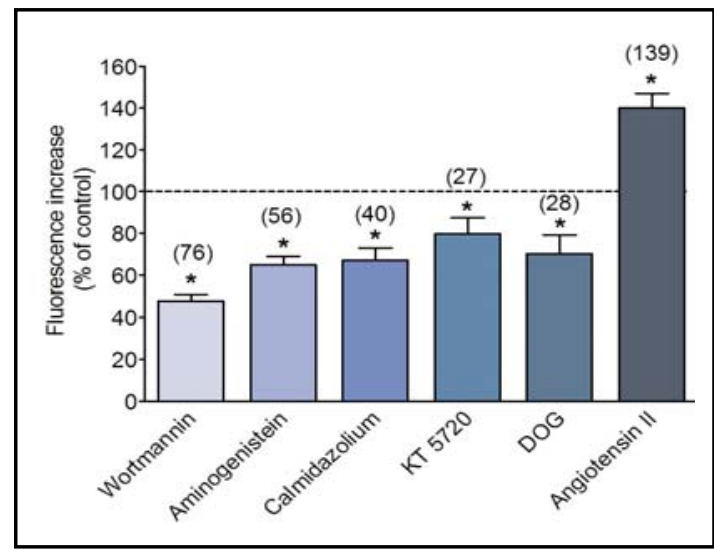

Fig. 2. Protein kinase dependent regulation of mOCT mediated $\mathrm{ASP}^{+}$-transport. Significant decrease of $\mathrm{ASP}^{+}$-uptake was seen with inhibition of PI3K (wortmannin, $0.1 \mu \mathrm{M}$ ), of p56 $6^{\text {lck }}$ tyrosine kinase (aminogenistein, $10 \mu \mathrm{M}$ ), of $\mathrm{Ca}^{2+} / \mathrm{CaM}$ (calmidazolium, $5 \mu \mathrm{M}$ ), PKA inhibition (KT5720, $1 \mu \mathrm{M}$ ) and PKC-stimulation (DOG, $1 \mu \mathrm{M}$ ) after an incubation time of $10 \mathrm{~min}$ at $37^{\circ} \mathrm{C}$. Angiotensin II (1 $\mathrm{nM}$ ) increased $\mathrm{ASP}^{+}$-uptake significantly. Data are given as mean values \pm SEM of initial cellular fluorescence increase in percent of controls with numbers of observations in parentheses; * indicates statistically significant differences compared to individual controls.

component of $\mathrm{ASP}^{+}$-uptake can be determined by subtracting the $\mathrm{TPA}^{+}$-dependent uptake from the total uptake. At $3 \mathrm{mM} \mathrm{TPA}^{+}$, a known substrate of mOCTs, the transport of $\mathrm{ASP}^{+}$is completely inhibited. Therefore the difference of both curves resulted in a saturation kinetic for the mOCT specific ASP+-uptake with a $\mathrm{k}_{\mathrm{m}}$-value of $4.6 \pm 0.5 \mu \mathrm{M}(\mathrm{n}=64-103)$. As cellular $\mathrm{ASP}^{+}$fluorescence was measured in arbitrary fluorescence units (a.u.) the $\mathrm{V}_{\max }$-value of 28.3 \pm 1.0 can only be compared relatively within this study with the technical settings kept constant (Fig. 1).

\section{Protein kinase dependent mechanisms of regulation}

In this work we further examined the cellular mechanisms of acute regulation of OC transport in freshly isolated mouse PTs. Phosphatidylinositol-3-kinase (PI3K), the $\mathrm{Ca}^{2+} /$ calmodulin complex $\left(\mathrm{Ca}^{2+} / \mathrm{CaM}\right), \mathrm{p} 56^{\text {lck }}$ tyrosine kinase $\left(\mathrm{p} 56^{\mathrm{lck}}\right)$, protein kinase A (PKA) and protein kinase $C$ (PKC) served as targets in this study. Confirming our first report [20] we again demonstrate an affection of OC transport in isolated mouse PTs by these pathways (Fig. 2) allowing us to study the mechanisms responsible for this regulation in tubules from the same animals under the same experimental conditions. These data suggest that $\mathrm{OC}$ transport in mouse PTs is activated by PI3K, p56 lck, PKA and $\mathrm{Ca}^{2+} / \mathrm{CaM}$ and inhibited by PKC. In the present consecutive study we focussed on the identification of the cellular mechanisms underlying this acute regulation of OC transport. Furthermore we put emphasis on the investigation of aspects of lysosomal degradation and of the cytoskeleton as vital cellular components and demonstrate that both are involved in the regulation of OC transport.

Regulation by phosphatidylinositol-3-kinase (PI3K)

Wortmannin $(0.1 \mu \mathrm{M})$, a known inhibitor of PI3K, reduced $\mathrm{ASP}^{+}$-uptake significantly by $48 \pm 3 \%(\mathrm{n}=76)$ after 10 min incubation (Fig. 2). As in these isolated PTs PI3K could 


\section{Cellular Physiology Cell Physiol Biochem 2012;30:269-281 \\ \begin{tabular}{ll|l} 
and BiOchemistry & $\begin{array}{l}\text { DOI: 10.1159/000339063 } \\
\text { Published online: June 19, } 2012\end{array}$ & $\begin{array}{l}\text { C 2012 S. Karger AG, Basel } \\
\text { www.karger.com/cpb }\end{array}$ \\
\cline { 2 - 3 } & Guckel/Ciarimboli/Pavenstädt/Schlatter: Regulation of Organic Cation Transport in
\end{tabular}}

\begin{tabular}{lccc}
\hline & $\mathrm{k}_{\mathrm{m}}(\mu \mathrm{M})$ & $\mathrm{V}_{\max }$ (a.u. $)$ & $\mathrm{n}$ \\
\hline Control & $4.6 \pm 0.5$ & $28.3 \pm 1.0$ & $67-103$ \\
Wortmannin $(0.1 \mu \mathrm{M})$ & $9.4 \pm 8.4$ & $19.3 \pm 7.7^{*}$ & $16-23$ \\
Aminogenistein $(10 \mu \mathrm{M})$ & $3.6 \pm 1.8$ & $18.5 \pm 2.9^{*}$ & $16-26$ \\
KT $5720(1 \mu \mathrm{M})$ & $4.4 \pm 3.9$ & $16.8 \pm 4.7^{*}$ & $27-29$ \\
DOG $(1 \mu \mathrm{M})$ & $4.3 \pm 3.3$ & $15.8 \pm 4.7^{*}$ & $21-27$ \\
Angiotensin $\Pi(1 \mathrm{nM})$ & $2.9 \pm 2.3^{*}$ & $33.8 \pm 7.7$ & $9-15$ \\
\hline
\end{tabular}

Table 1. Effects of protein kinase inhibition/activation on $\mathrm{ASP}^{+}$transport kinetics. Mean values \pm SEM with $n$ indicating number of observations; * indicates significantly different to control.

Fig. 3. Effects of protein kinase dependent regulation of $\mathrm{ASP}^{+}$-uptake on transport kinetics. Kinetics of mOCT-dependent initial $\mathrm{ASP}^{+}$-uptake without (Control) and with incubation with agonists and antagonists for $10 \mathrm{~min}$ at $37^{\circ} \mathrm{C}$. Specific uptake rates were obtained as depicted in figure 1 . Wortmannin $(0.1 \mu \mathrm{M})$, aminogenistein $(10 \mu \mathrm{M})$, DOG $(1 \mu \mathrm{M})$ and $\operatorname{KT5720}(1 \mu \mathrm{M})$ influenced the trafficking (lowered $\mathrm{V}_{\text {max }}$ ) of mOCTs whereas angiotensin II (1 $\mathrm{nM})$ modulated the substrate affinity (increased $\mathrm{k}_{\mathrm{m}}$ ) of $\mathrm{ASP}^{+}$transport. Data are given as mean values \pm SEM. Calculated $\mathrm{k}_{\mathrm{m}}$ and $\mathrm{V}_{\max }$-values and numbers of observations are summarized in Table 1.

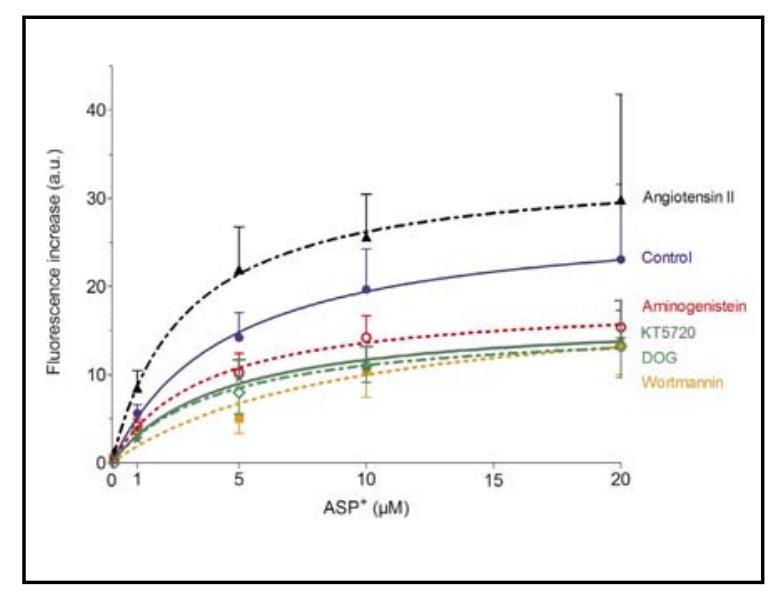

not be further activated by insulin, a known activator in the insulin receptor pathway, as demonstrated by us before [20], we used EGF (50 ng/ml), IGF-1 (50 ng/ml) and IL-1 $\alpha$ (10 $\mathrm{ng} / \mathrm{ml}$ ) as possible stimulators of PI3K. Also these agonists did not significantly stimulate $\mathrm{ASP}^{+}$-uptake (data not shown) again indicating that PI3K is already maximally endogenously active in these isolated tubules and stimulates OC transport in PTs of mice.

To find out whether the observed inhibitory effect of wortmannin on OC transport arises from an altered substrate affinity of mOCTs or is rather based on changes in transport capacity via mOCT trafficking from and to the plasma membrane, kinetic measurements with $\mathrm{ASP}^{+}$as substrate were performed. Using the same experimental approach as depicted in figure 1, incubating PTs with wortmannin $(0.1 \mu \mathrm{M})$ for $10 \mathrm{~min}$ before starting the experiments did not lead to a significant change in the $\mathrm{k}_{\mathrm{m}}$-value for $\mathrm{ASP}^{+}$, but to a significantly reduced $\mathrm{V}_{\max }$-value (Table 1) as calculated from the mOCT-dependent $\mathrm{ASP}^{+}$dependent uptake curve shown in Figure 3. This suggests that PI3K influences OC transport by trafficking or turnover effects without modifying substrate affinity.

Regulation by angiotensin II and the $\mathrm{Ca}^{2+} /$ CaM complex

Furthermore we studied the calmodulin associated regulation of mOCTs. Angiotensin II $(1 \mathrm{nM})$ raises intracellular $\mathrm{Ca}^{2+}$, activates the $\mathrm{Ca}^{2+} / \mathrm{CaM}$ complex and thereby stimulated $\mathrm{ASP}^{+}$-uptake as shown by us before [20]. In the present study angiotensin II (1 nM) increased $\mathrm{ASP}^{+}$-uptake by $40 \pm 7 \%(\mathrm{n}=139)$ after $10 \mathrm{~min}$ incubation (Fig. 2). The observed angiotensin II effect could again be abolished by coincubation with calmidazolium ( $5 \mu \mathrm{M})$, a known inhibitor of the $\mathrm{Ca}^{2+} / \mathrm{CaM}$ complex, which reduced $\mathrm{ASP}^{+}$-uptake in the presence of angiotensin II by $33 \pm 6 \%(n=40)$, suggesting a partial endogenous activation of the $\mathrm{Ca}^{2+} / \mathrm{CaM}$ complex in these PTs. 


\section{Cellular Physiology Cell Physiol Biochem 2012;30:269-281

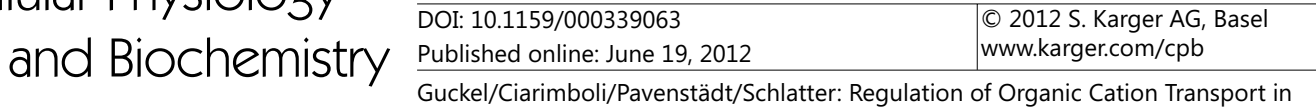 Guckel/Ciarimboli/Pavenstädt/Schla}

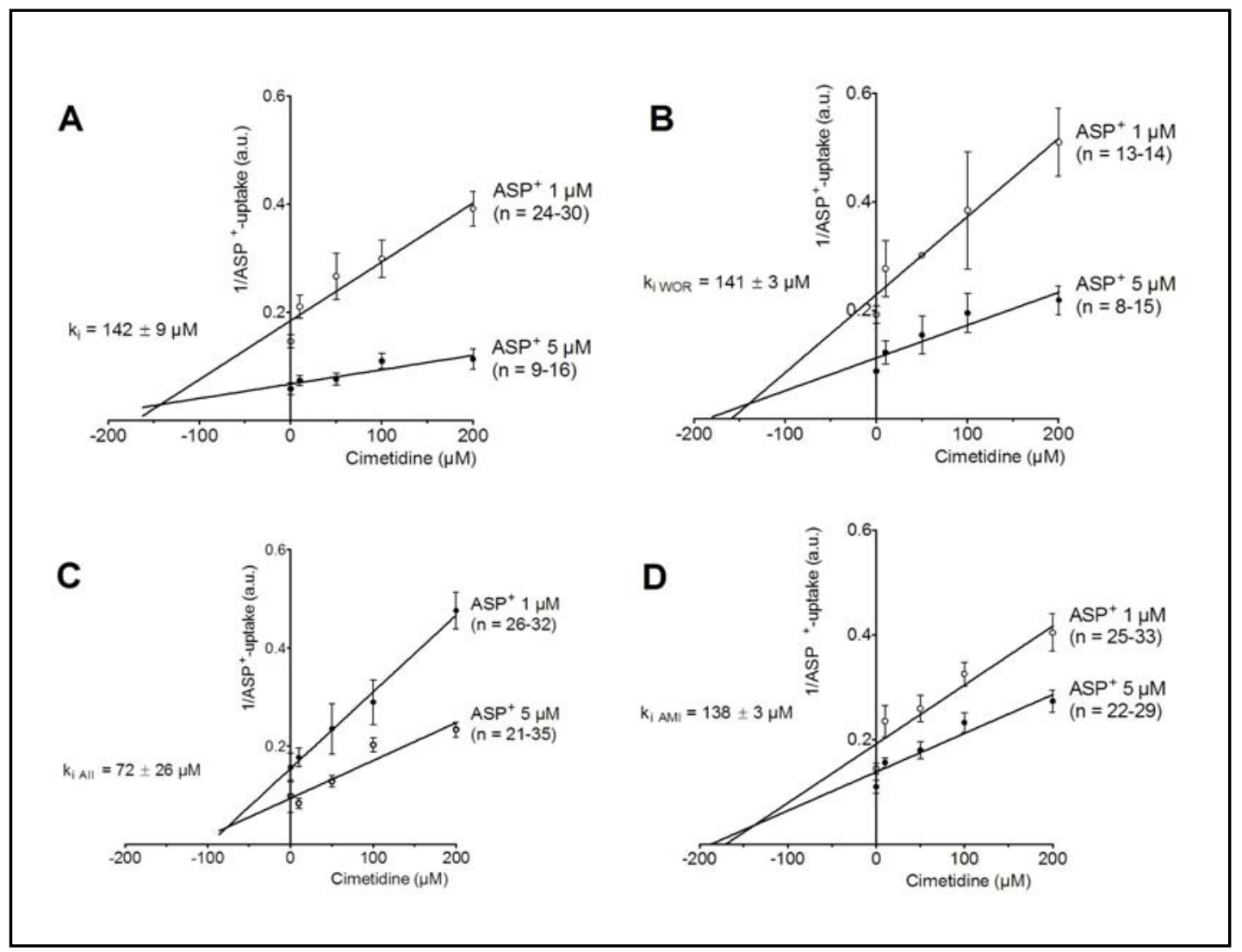

Fig. 4. Protein kinase-dependent effects on $\mathrm{k}_{\mathrm{i}}$ of cimetidine. A. Dixon plot analyses of the inhibition of $\mathrm{ASP}^{+}$-uptake $(1$ or $5 \mu \mathrm{M})$ by cimetidine were performed to determine the inhibition constant $\left(\mathrm{k}_{\mathrm{i}}\right)$. $\mathrm{k}_{\mathrm{i}}$ was determined by the negative concentration at the point of intersection of the regression lines evoked by the two $\mathrm{ASP}^{+}$concentrations. B. Dixon plot analyses of the inhibition of $\mathrm{ASP}^{+}$-uptake by cimetidine under incubation with wortmannin $(0.1 \mu \mathrm{M}, 10 \mathrm{~min})$ resulted in no significantly altered $\mathrm{k}_{\mathrm{i}}$-value compared to the control. C. Dixon plot analyses of the inhibition of $\mathrm{ASP}^{+}$-uptake by cimetidine under incubation with angiotensin II (1 nM, $10 \mathrm{~min}$ ) resulted in a significantly reduced $\mathrm{k}_{\mathrm{i}}$-value compared to the control. D. Dixon plot analyses of the inhibition of $\mathrm{ASP}^{+}$-uptake by cimetidine under incubation with aminogenistein $(10 \mu \mathrm{M}$, $10 \mathrm{~min}$ ) did not significantly alter the $\mathrm{k}_{\mathrm{i}}$-value compared to the control. Data are given as mean values $\pm \mathrm{SEM}$ of cellular fluorescence increase with numbers of observations in parentheses.

$\mathrm{ASP}^{+}$-uptake kinetics were determined after incubation with angiotensin II and compared to those under unstimulated control conditions (Fig. 3). Under angiotensin II stimulation a significantly reduced $\mathrm{k}_{\mathrm{m}}$-value but no changes in the $\mathrm{V}_{\max }$-value were calculated (Table 1 ). Therefore angiotensin II might induce conformational changes at the substrate-binding site of mOCTs, which lead to an increased substrate affinity.

Regulation by $p 56$ tyrosine kinase ( $p 56^{I c k}$ )

Aminogenistein inhibited $\mathrm{p} 56^{\mathrm{Ick}}$ and thus reduced $\mathrm{ASP}^{+}$-uptake in our previous report [20]. In the present study aminogenistein $(10 \mu \mathrm{M})$ decreased $\mathrm{ASP}^{+}$-uptake by $35 \pm 4 \%$ $(\mathrm{n}=56)$ (Fig. 2). Analysing the kinetics of $\mathrm{ASP}^{+}$-uptake after incubation with aminogenistein (Fig. 3) resulted in no change in $\mathrm{k}_{\mathrm{m}}$ - and a significantly reduced $\mathrm{V}_{\max }$-value (Table 1). As only the $V_{\max }$-value differed significantly from the unstimulated control this emphasizes that this inhibitory effect is probably also evoked by modifying transporter trafficking.

Regulation by protein kinase A (PKA) and protein kinase C (PKC)

Sn-1,2-dioctanoyl glycerol (DOG), a membrane permeable analogue of diacyl glycerol, which is known to stimulate PKC and KT5720, which inhibits PKA, both reduced ASP+-uptake 


\section{Cellular Physiology and Biochemistry \\ Cell Physiol Biochem 2012;30:269-281 \\ \begin{tabular}{l|l}
\hline DOI: 10.1159/000339063 & (C) 2012 S. Karger AG, Basel
\end{tabular} \\ Published online: June 19, 2012

Fig. 5. Influence of bafilomycin on $\mathrm{ASP}^{+}$transport. Concentration dependent decrease of $\mathrm{ASP}^{+}$-uptake by bafilomycin after $10 \mathrm{~min}$ of incubation. Data are given as mean values \pm SEM of cellular fluorescence increase in percent of controls with numbers of observations in parentheses; * indicates statistically significant effects.

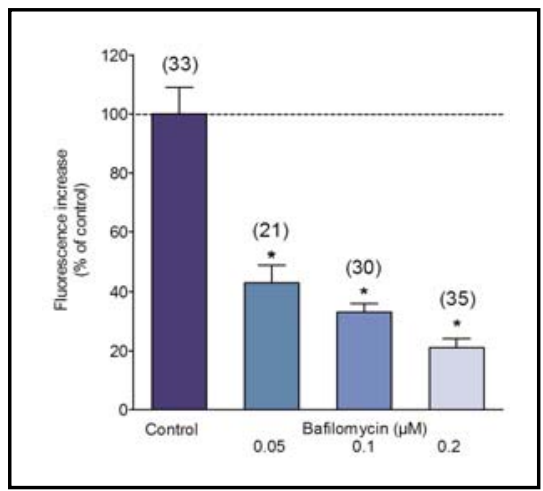

significantly in our previous report [20] and again in this study by $30 \pm 9 \%(\mathrm{n}=28)$ and 20 $\pm 8 \%(\mathrm{n}=27)$, respectively (Fig. 2). ASP+-kinetic measurements (Fig. 3) unveiled that these protein kinase signalling pathways also regulate OCT mediated transport via trafficking effects because DOG and KT5720 significantly reduced the $\mathrm{V}_{\max }$-values for $\mathrm{ASP}^{+}$, without altering substrate affinity (Table 1 ).

\section{ASP $P^{+}$transport inhibition by cimetidine}

To further check and confirm the results on mechanisms of regulation gained from the $\mathrm{ASP}^{+}$-kinetic measurements described above we implemented Dixon plot analyses to evaluate the inhibition constant $\left(\mathrm{k}_{\mathrm{i}}\right)$ for the inhibition of $\mathrm{ASP}^{+}$-uptake by the known competitor substrate cimetidine. We plotted the reciprocal $\mathrm{ASP}^{+}$-uptake values obtained at increasing concentrations of cimetidine at two substrate concentrations ( $\mathrm{ASP}^{+} 1$ and $5 \mu \mathrm{M}$ ). This indirect way of kinetic analysis is required, as cimetidine cannot be measured directly using a fluorescence system. For cimetidine we obtained a $\mathrm{k}_{\mathrm{i}}$-value of $142 \pm 9 \mu \mathrm{M}(\mathrm{n}=9-30)$ (Fig. 4a).

Effect of the PI3K: To confirm the mode of regulation of ASP+-transport by protein kinases we determined whether these kinases affect the $\mathrm{k}_{\mathrm{i}}$-value for cimetidine. The $\mathrm{k}_{\mathrm{i}}$-value for cimetidine of $141 \pm 3 \mu \mathrm{M}(\mathrm{n}=8$-15) obtained after incubation with wortmannin $(0.1 \mu \mathrm{M})$ did not differ significantly from that under control conditions (Fig. 4b).

Effect of angiotensin II: The $\mathrm{k}$-value for cimetidine of $72 \pm 26 \mu \mathrm{M} \quad(\mathrm{n}=21-35)$ achieved from Dixon plot analyses after incubation with angiotensin II (1 nM) differed significantly from that obtained under control conditions, emphasizing the assumption obtained from $\mathrm{ASP}^{+}$kinetics, that $\mathrm{OC}$ transport via the $\mathrm{Ca}^{2+} / \mathrm{CaM}$ pathway is regulated by an altered substrate affinity (Fig. 4c).

Effect of the p56 tyrosine kinase: Dixon plot analyses of the $\mathrm{k}_{\mathrm{i}}$-value for cimetidine after incubation with aminogenistein $(10 \mu \mathrm{M})$ resulted in no significant change in this value (138 $\pm 3 \mu \mathrm{M} ; \mathrm{n}=22-33$ ) compared to controls. Therefore these findings underscore the conclusion that the regulation of $\mathrm{OC}$ transport via the $\mathrm{PI} 3 \mathrm{~K}$ and the $\mathrm{p} 56^{\text {Ick }}$ pathways is mediated by trafficking or turnover effects, but not by modification of substrate affinities (Fig. 4d).

\section{Involvement of proteolytic pathways}

We further examined the impact of proteolytic pathways on the regulation of OC transport by using bafilomycin. Bafilomycin inhibits the vacuolar type of $\mathrm{H}^{+}$-ATPase reversibly and thus stops early endosomal recycling and lysosomal protein degradation. The incubation of PTs with bafilomycin led to a concentration dependent reduction of ASP+-uptake (Fig. 5).

Bafilomycin and angiotensin II. Under simultaneous incubation of PTs with bafilomycin $(0.2 \mu \mathrm{M})$ and angiotensin II $(1 \mathrm{nM})$ as stimulator of the $\mathrm{Ca}^{2+} / \mathrm{CaM}$ complex we could still demonstrate the stimulating effect of angiotensin II even on the bafilomycin induced reduced level of OC transport (Fig. 6a). These results confirm the above findings that the stimulating effect of angiotensin II on OC transport is probably based on an increased substrate affinity of the transporters in the plasma membrane whereas the bafilomycin dependent proteolysis reduces the number of active transporters in the plasma membrane. 


\section{Cellular Physiology \\ Cell Physiol Biochem 2012;30:269-281 \\ and Biochemistry \\ \begin{tabular}{l|l}
\hline DOI: $10.1159 / 000339063$ & C 2012 S. Karger AG, Basel \\
Published online: June 19, 2012 & www.karger.com/cpb
\end{tabular} \\ Published online: June 19, 2012 \\ Guckel/Ciarimboli/Pavenstädt/Schlatter: Regulation of Organic Cation Transport in Isolated Mouse Proximal Tubules}
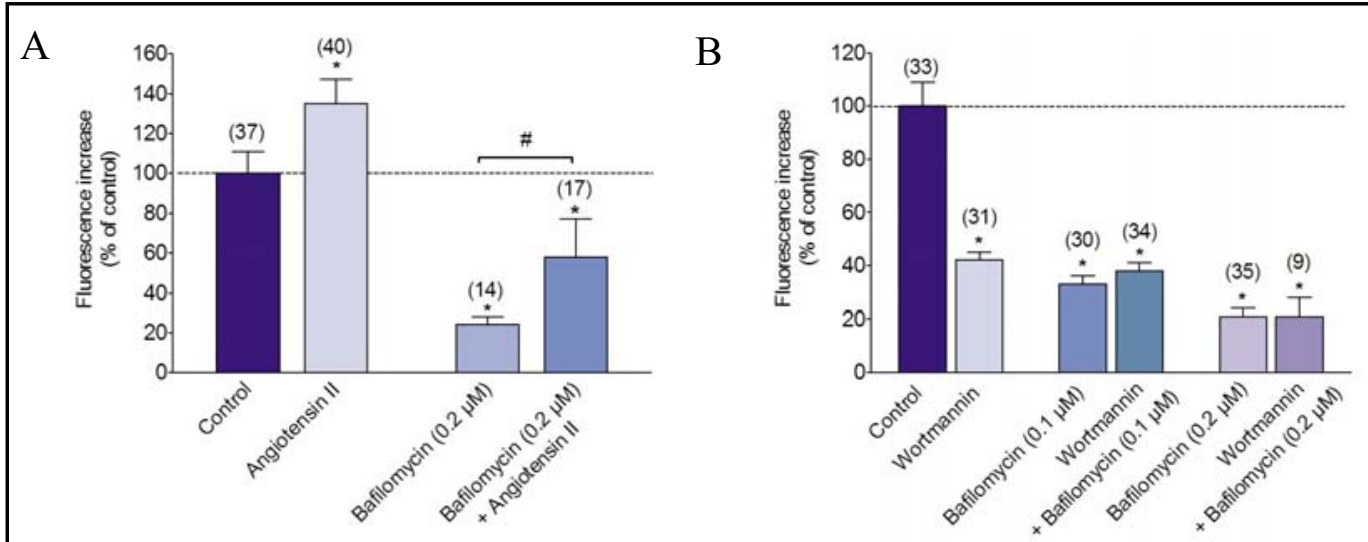

Fig. 6. Influence of bafilomycin on the regulation of $\mathrm{ASP}^{+}$transport. Effects of incubation with bafilomycin on the effects of angiotensin II or wortmannin on $\mathrm{ASP}^{+}$-transport. A. The effect of angiotensin II (1 nM, $10 \mathrm{~min})$ on $\mathrm{ASP}^{+}$-uptake was not prevented by bafilomycin incubation $(0.2 \mu \mathrm{M}, 10 \mathrm{~min})$. B. The inhibitory effect of wortmannin $(0.1 \mu \mathrm{M}, 10 \mathrm{~min})$ on $\mathrm{ASP}^{+}$-uptake was inhibited at two concentrations of bafilomycin indicating the concerted interaction of both substances with trafficking. Data are given as mean values \pm SEM of cellular fluorescence increase in percent of controls with numbers of observations in parentheses; * indicates statistically significant effects compared to control; \# denotes significant difference between indicated bars.

Bafilomycin and wortmannin. We examined the interaction of bafilomycin with the $\mathrm{PI} 3 \mathrm{~K}$ dependent regulation of $\mathrm{ASP}^{+}$-uptake in the same way. As wortmannin reduced $\mathrm{ASP}^{+}$ uptake (Fig. 2) we used two concentrations of bafilomycin $(0.1$ or $0.2 \mu \mathrm{M})$ to test whether the effect of wortmannin $(0.1 \mu \mathrm{M})$ can still be observed under simultaneous incubation with bafilomycin. Under both bafilomycin concentration no further change of $\mathrm{ASP}^{+}$-uptake was induced by wortmannin (Fig. 6b), which again suggests that the PI3K mediated regulation of OC transport involves a proteolytic pathway dependent trafficking.

\section{Involvement of the cytoskeleton}

We next focussed on the involvement of components of the cytoskeleton in the regulation of OC transport. For this purpose we chose colchicine due to its destructive impact on microtubules. A 30 min incubation with colchicine $(100 \mu \mathrm{M})$ reduced ASP'-uptake significantly by $38 \pm 8 \%(n=33)$ (Fig. 7), suggesting a significant role of the cytoskeleton in the regulation of mOCTs. To further demonstrate that this component does not influence the properties of mOCTs residing in the plasma membrane we examined whether the angiotensin II $(1 \mathrm{nM})$ mediated effect on $\mathrm{ASP}^{+}$-affinity can still be observed. As summarized in Figure 7 even after colchicine incubation the stimulatory effect of angiotensin II was still present.

\section{Discussion}

The kidneys are involved in the excretion of many endogenous and exogenous organic cations. The levels of these substances in blood vary depending on metabolism and food or drug intake. Probably to adjust excretion of especially the endogenous substrates to such variations in plasma concentrations mechanism of short- as well as long-term regulation of the respective transport proteins are developed. Consequently such mechanisms will also influence the uptake or excretion of exogenous drugs or toxins. Good knowledge about the structure and function of different OCT isoforms in various species could already be gained. Within the last years special focus was put on the investigation of regulatory mechanisms of OCTs $[2,4,14]$. However, data on acute regulation of OC transport in the intact organ or 


\section{Cellular Physiology $\quad$ Cell Physiol Biochem 2012;30:269-281

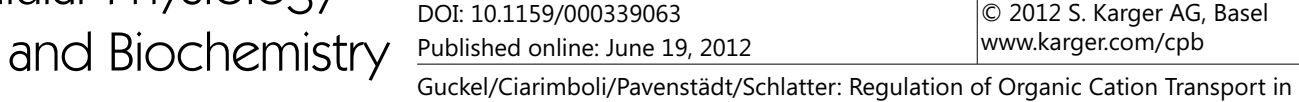 Isolated Mouse Proximal Tubules}

Fig. 7. Involvement of the cytoskeleton in acute regulation of $\mathrm{ASP}^{+}$transport by angiotensin II. The incubation of PTs with colchicine $(100 \mu \mathrm{M})$ for 30 min led to a significantly decreased $\mathrm{ASP}^{+}$-uptake, suggesting the role of an intact microtubular network for OCT-mediated transport. Under simultaneous incubation with colchicine and angiotensin II (1 $\mathrm{nM}$ ) the stimulating angiotensin II effect could still be observed, in line with the observed absence of trafficking effects on OC transport by this pathway. Data are given as mean values \pm SEM of cellular fluorescence increase in percent of controls with numbers of observations in parentheses; ${ }^{*}$ indicates statistically significant effects compared to control; \# denotes significant difference between indicated bars.

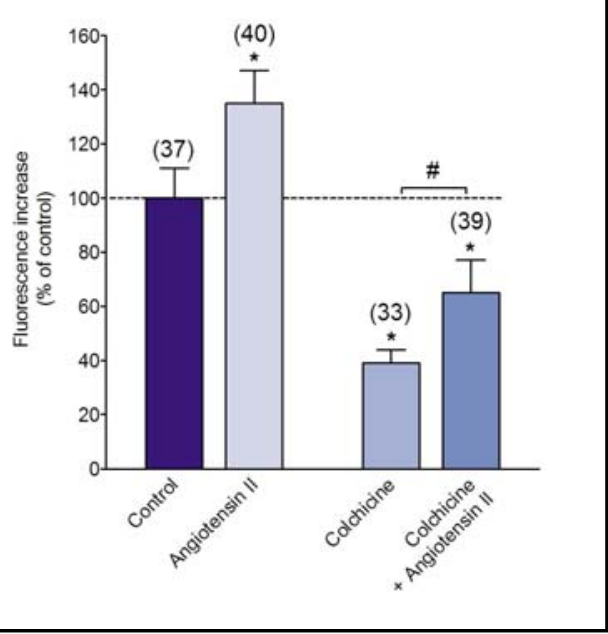

in isolated proximal tubules are scarce and are limited to single studies from rabbit [25], rat [23] and human PTs [22]. Although transgenic mice play a preeminent role in several physiological, pharmacological, or translational studies, data on functional properties of OC transport in PTs of mice, especially concerning mechanisms of short-term regulation, are not yet sufficiently described. Only recently we could report the first basic data on OCT regulation in isolated mouse proximal tubules [20]. Concerning the lack of respective studies as well as the well-known fact of species, organ and genotype dependent differences of OCTs [14] we attempted to further examine the mechanisms involved in the complex pattern underlying acute regulation of $\mathrm{OC}$ transport across the basolateral membrane of freshly isolated mouse PTs.

\section{Determination of kinetics of substrate transport}

Since the positively charged fluorescent dye $\mathrm{ASP}^{+}$, a model substrate of OCTs, is not transported by any other OC transporter expressed at the basolateral membrane of PTs our data exclusively depict $\mathrm{ASP}^{+}$-transport mediated by OCTs. In order to calculate transport kinetics saturable transport of $\mathrm{ASP}^{+}$solely mediated by mOCTs had to be distinguished from OCT-independent $\mathrm{ASP}^{+}$-uptake. mOCT dependent $\mathrm{ASP}^{+}$-uptake was obtained by applying $\mathrm{TPA}^{+}$ ( $3 \mathrm{mM}$ ) to the injection solution, which completely blocks mOCT-mediated ASP+-uptake even at a concentration of $1 \mathrm{mM}[20]$. The $\mathrm{k}_{\mathrm{m}}$-value of approximately $5 \mu \mathrm{M}$ for $\mathrm{ASP}^{+}$under control conditions obtained in the present study is in the same range as that reported by us before for isolated mouse PTs [20], human proximal tubules [22] or other OCT isoforms expressed in HEK-293 cells $[15,26]$. As OCTs accept a wide spectrum of structurally highly different substrates and different binding sites for these substrates have been suggested [27], we tested whether the observed regulatory effects on $\mathrm{ASP}^{+}$kinetics can also be seen using a structurally different classical OCT substrate. Therefore we performed Dixon plot analyses. While $\mathrm{k}_{\mathrm{m}}$ - and $\mathrm{k}_{\mathrm{i}}$-values can be determined as absolute concentrations and therefore compared within this study but also to respective data in the literature, the $\mathrm{V}_{\max }$-values obtained in this study are arbitrary fluorescence values, which depend on the experimental and technical conditions and thus, can only be compared within this study.

\section{Effects of protein kinases on transport kinetics}

$P I 3 K$. The involvement of PI3K in the regulation of OC transport has been reported for hOCT2 [21, 28] or rOCT2 [23] stably expressed in HEK-293 cells as well as for human (Schlatter E. and Ciarimboli G., unpublished results) and mouse PTs [20]. Due to the results of our kinetic measurements performed in this study, i.e. effects only on $V_{\max }$ and not on $\mathrm{k}_{\mathrm{m}}$ or $\mathrm{k}_{\mathrm{i}}$ we suggest that the inhibitory effect of wortmannin is based on trafficking or turnover 


\section{Cellular Physiology $\quad$ Cell Physiol Biochem 2012;30:269-281

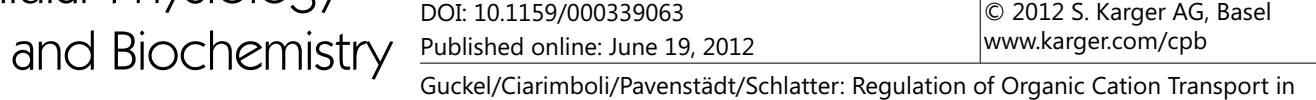 \\ Guckel/Ciarimboli/Pavenstädt/Sch
Isolated Mouse Proximal Tubules}

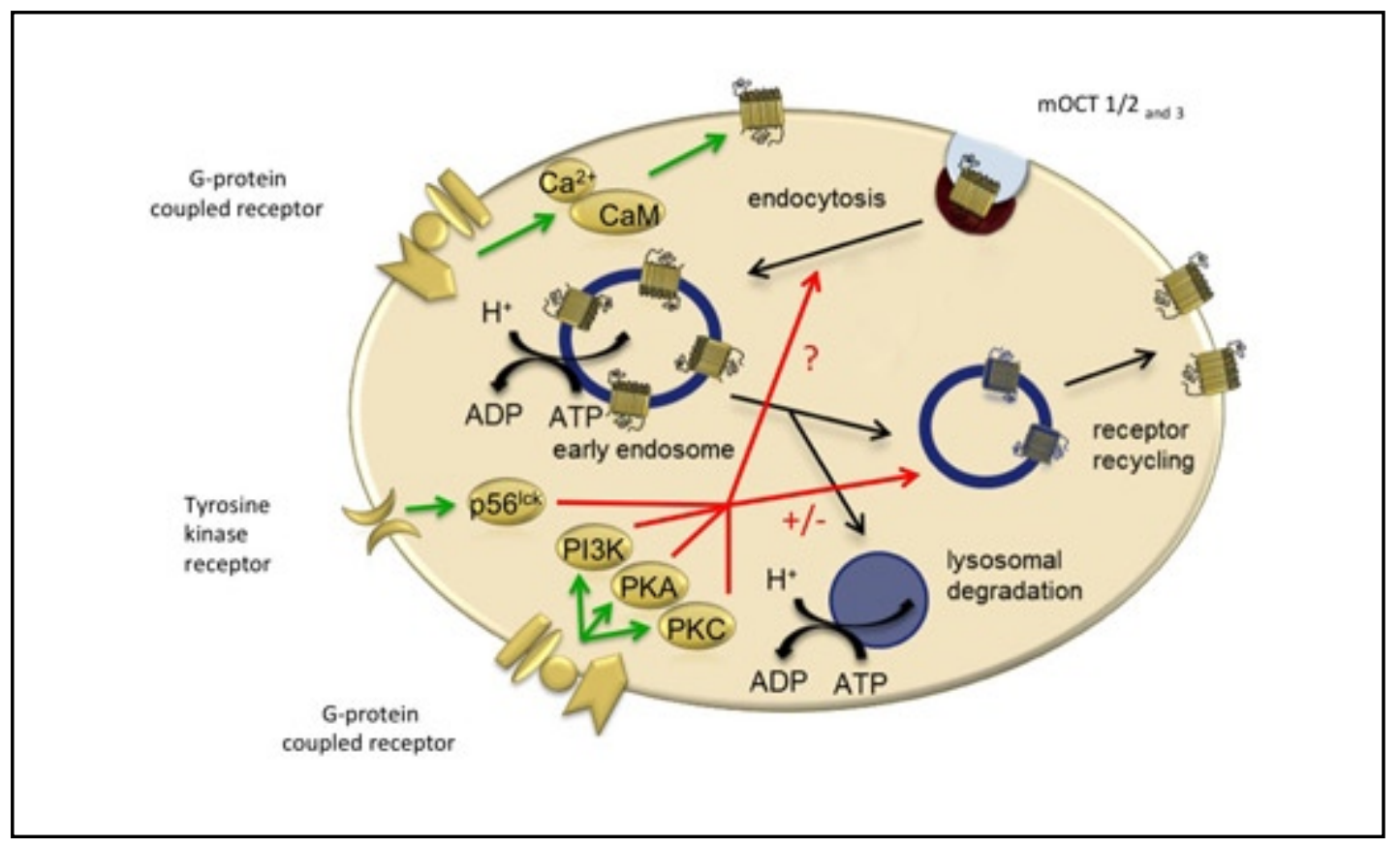

Fig. 8. Suggested mechanisms of acute regulation of mOCTs. Schematic representation of affinity and trafficking effects induced by the depicted signalling pathways. Reguation of mOCTs by the p56Ick, PI3K, PKA and PKC pathways seems to involve an altered number of transporters in the plasma membrane due to a decreased OCT trafficking to the membrane and/or a high turnover rate of OCT-retrieval from the membrane, whereas the angiotensin II dependent regulation of mOCTs via the $\mathrm{Ca}^{2+} / \mathrm{CaM}$ pathway rather influences the substrate affinity of mOCTs.

effects of PI3K. This may be e.g. due to a deceleration of intracellular trafficking of mOCTs to the membrane or an accelerated retrieval and degradation of mOCTs to or from the membrane and thus, a decreased amount of active transporters expressed in the cell membrane.

In line with our previous findings that insulin, a known activator in the insulin receptor pathway, does not further stimulate PI3K in these freshly isolated PTs, EGF, IGF-1 and IL$1 \alpha$ did also not lead to an altered $\mathrm{ASP}^{+}$-uptake. Thus, we suggest that PI3K is already endogenously active and stimulates OC transport in these freshly isolated mouse PTs via an altered trafficking to or from the plasma membrane. Similar findings have been observed by us for rOCT2 [23] expressed in HEK-293 cells whereas opposite findings have been revealed for hOCT2, which seems to be inhibited by PI3K $[21,28]$.

Angiotensin II. Angiotensin II activates multiple signalling pathways including the $\mathrm{Ca}^{2+} /$ CaM complex as well as the PKC signalling pathway. Our present findings on a $\mathrm{Ca}^{2+} / \mathrm{CaM}^{2}$ dependent regulation are in line with observations published for rOCT2 [23], hOCT1 [29], hOCT2 [21] and hOCT3 [30]. Due to the fact that calmidazolium antagonized the angiotensin II effect we conclude that the PKC signalling pathway seems to play a subordinated role in transporter regulation by angiotensin II in mouse PTs as already demonstrated for HEK293 cells expressing hOCT1 and hOCT2 $[28,29]$. Due to the observed lower respective $\mathrm{k}_{\mathrm{m}}$ and decreased $\mathrm{k}_{\mathrm{i}}$-values with no change in the $\mathrm{V}_{\max }$-value we suggest that angiotensin II has an impact on the substrate affinity of mOCTs by probably inducing conformational changes at the substrate binding-sites and thus, increasing the transport rate of the transporters. A similar effect on substrate affinity could be demonstrated by us before for the effect of PKC on rOCT1 $[17,24]$. Opposite effects have been reported by us for hOCT2 expressed in HEK293 cells [28], where an inhibition of the $\mathrm{Ca}^{2+} / \mathrm{CaM}$ complex led to a significantly decreased $\mathrm{V}_{\max }$-value, which indicates a reduction of membrane associated hOCT2 [28]. Taken together, these findings once more underscore species dependent differences between OCTs. 


\section{Cellular Physiology $\quad$ Cell Physiol Biochem 2012;30:269-281 \\ \begin{tabular}{ll|l} 
and Biochemistry $10.1159 / 000339063$ & $\begin{array}{l}\text { O 2012 S. Karger AG, Basel } \\
\text { www.karger.com/cpb }\end{array}$ \\
\cline { 2 - 3 } & Published online: June 19, 2012 & Guckel/Ciarimboli/Pavenstädt/Schlatter: Regulation of Organic Cation Transport in
\end{tabular} \\ Guckel/Ciarimboli/Pavenstädt/Schl
Isolated Mouse Proximal Tubules}

Aminogenistein. In this study aminogenistein, an inhibitor of $\mathrm{p} 56^{\text {lck }}$, reduced ASP'-uptake significantly, emphasizing our findings reported before [20] and indicating endogenous activation of mOCTs by this kinase. Moreover these observations gained from mouse PTs are in line with the effects of aminogenistein observed for rOCT1 [17], rOCT2 [23] and hOCT1 [29]. Due to the fact that the $\mathrm{k}_{\mathrm{m}}$-value for $\mathrm{ASP}^{+}$and the $\mathrm{k}_{\mathrm{i}}$-value for cimetidine were not altered by aminogenistein, whereas the $\mathrm{V}_{\max }$-value for $\mathrm{ASP}^{+}$was significantly decreased, these results indicate that also the regulation of mOCTs by p56 $6^{\text {lck }}$ is probably mediated by trafficking effects.

\section{Involvement of proteolytic pathways}

To obtain more inside into the mechanisms responsible for the observed apparent trafficking effects induced by PI3K-, $\mathrm{Ca}^{2+} / \mathrm{CaM}$-, and $\mathrm{p}^{\mathrm{k}} 6^{\mathrm{lck}}$-activation, effects of endosomal and lysosomal function and microtubule organisation were studied. Bafilomycin, which is known as a macrolide antibiotic isolated from Streptomyces sp., inhibits both endogenous early endosomal recycling and lysosomal protein degradation by highly specifically interfering with the $\mathrm{H}^{+}$-ATPase and thus, averts the acidification of organelles belonging to the central vacuolar system. The ability of vacuolar organelles to generate and maintain an acidic $\mathrm{pH}$ plays a crucial role in a variety of critical cellular functions, e.g. for the proper function of vesicular transport of proteins, for the fusion between autophagosomes and lysosomes and thus, for membrane protein recycling or its subsequent degradation. The involvement of the vacuolar $\mathrm{H}^{+}$-ATPase in the process of proximal renal tubule endocytosis and protein degradation has also been demonstrated in previous studies [31,32]. Inhibition of vacuolar $\mathrm{H}^{+}$-ATPase by bafilomycin reduced $\mathrm{ASP}^{+}$-uptake in the present study. This effect seems to be due to a reduced number of mOCTs in the plasma membrane as a result of decreased OCT trafficking to the membrane. It also suggests a high turnover rate of OCTretrieval from the membrane under normal conditions. Therefore it could be speculated that regulation of mOCTs by PI3K could also involve an altered number of transporters in the plasma membrane due to a change in the turnover rate rather than an influence on the substrate affinity of mOCTs (Fig.8). This assumption was confirmed by the fact that PTs incubated with bafilomycin did no longer respond to inhibition of PI3K by wortmannin. In contrast, as stimulation of $\mathrm{Ca}^{2+} / \mathrm{CaM}$ by angiotensin II only decreased $\mathrm{k}_{\mathrm{m}}$ - and $\mathrm{k}_{\mathrm{i}}$-values but not $\mathrm{V}_{\text {max }}$ for $\mathrm{ASP}^{+}$and cimetidine, respectively, the effect of angiotensin II was still observed in the presence of bafilomycin. Thus, despite the strong reduction in the amount of active OC transporters in the plasma membrane by bafilomycin angiotensin II was still able to increase transport activity probably via a change in the affinity of the remaining mOCTs in the plasma membrane

Sodium phosphate type two cotransporters (NpT2a, NpT2c) similarly underlie complex regulatory mechanisms by diverse stimuli, which primarily lead to an altered expression of these transporters in the apical membrane of renal proximal tubule cells [33-35]. The vacuolar $\mathrm{H}^{+}$-ATPase seems to be involved in transporter trafficking of NpT2a in and out of the apical membrane [36]. Therefore the vacuolar $\mathrm{H}^{+}$-ATPase probably plays a crucial role for plasma membrane trafficking of various transporters including mOCTs.

\section{Involvement of the cytoskeleton}

Finally we addressed the question whether the cytoskeleton is involved in acute regulation of OCTs as well. Because of the observed inhibitory effect of colchicine, which destroys microtubules by inhibiting their polymerisation at the plus end, it has to be postulated that also an intact cytoskeleton is important for normal activity of OC transport. As expected, the stimulatory effect of angiotensin II, which altered substrate affinity but not trafficking of mOCTs, was still preserved under colchicine.

In conclusion, we examined the molecular mechanisms of protein kinase dependent short-term regulation of mOCTs in isolated proximal tubules. We demonstrate a modulation 


\section{Cellular Physiology Cell Physiol Biochem 2012;30:269-281 \begin{tabular}{ll|l} 
and BiOChemistry & $\begin{array}{l}\text { DOI: 10.1159/000339063 } \\
\text { Published online: June 19, } 2012\end{array}$ & $\begin{array}{l}\text { C 2012 S. Karger AG, Basel } \\
\text { www.karger.com/cpb }\end{array}$ \\
$\begin{array}{l}\text { Guckel/Ciarimboli/Pavenstädt/Schlatter: Regulation of Organic Cation Transport in } \\
\text { Isolated Mouse Proximal Tubules }\end{array}$
\end{tabular}}

of mOCT trafficking to/from the plasma membrane by PI3K, p56 $6^{\text {lck }}$, PKA or PKC and an involvement of the cytoskeletal network in the regulation of mOCT-dependent transport in freshly isolated mouse proximal tubules. In addition we could demonstrate that activation of $\mathrm{Ca}^{2+} / \mathrm{CaM}$ via angiotensin II increases the substrate affinity of these transporters without modifying its trafficking. Certainly additional studies are necessary to further unravel the complex mechanisms of mOCT regulation by direct effects on transporters or indirect trafficking effects in proximal tubules of the kidney.

\section{Acknowledgements}

The authors are grateful to the expert technical support by Bernadette Gelschefarth, Ute Neugebauer, Indra Raj and Rita Schröter. This study was supported by a grant of the Deutsche Forschungsgemeinschaft (Ci 107/4-2).

\section{References}

1 Ciarimboli G: Organic cation transporters. Xenobiotica 2008;38:936-971.

2 Ciarimboli G, Schlatter E: Regulation of organic cation transport. Pflugers Arch 2005;449:423-441.

3 Berkhin EB, Humphreys MH: Regulation of renal tubular secretion of organic compounds. Kidney Int 2001;59:17-30.

4 Koepsell H, Endou H: The SLC22 drug transporter family. Pflugers Arch 2004;447:666-676.

5 Bourdet DL, Pritchard JB, Thakker DR: Differential substrate and inhibitory activities of ranitidine and famotidine toward human organic cation transporter 1 (hOCT1; SLC22A1), hOCT2 (SLC22A2), and hOCT3 (SLC22A3). J Pharmacol Exp Ther 2005;315:1288-1297.

6 Ciarimboli G, Ludwig T, Lang D, Pavenstädt H, Koepsell H, Piechota HJ, Haier J, Jaehde U, Zisowsky J, Schlatter E: Cisplatin nephrotoxicity is critically mediated via the human organic cation transporter 2 . Am J Pathol 2005;167:1477-1484.

7 Ciarimboli G, Holle SK, Vollenbröker B, Hagos Y, Reuter S, Burckhardt G, Bierer S, Herrmann E, Pavenstädt H, Rossi R, Kleta R, Schlatter E: New clues for nephrotoxicity induced by ifosfamide: preferential renal uptake via the human organic cation transporter 2. Mol Pharm 2011;8:270-279.

8 Ciarimboli G, Deuster D, Knief A, Sperling M, Holtkamp M, Edemir B, Pavenstädt H, Lanvers-Kaminsky C, am Zehnhoff-Dinnesen A, Schinkel AH, Koepsell H, Jürgens H, Schlatter E: Organic cation transporter 2 mediates cisplatin-induced oto- and nephrotoxicity and is a target for protective interventions. Am J Pathol 2010;176:1169-1180.

9 Ciarimboli G: Role of organic cation transporters in drug-induced toxicity. Expert Opin Drug Metab Toxicol 2011;7:159-174.

10 Hasannejad H, Takeda M, Narikawa S, Huang XL, Enomoto A, Taki K, Niwa T, Jung SH, Onozato ML, Tojo A, Endou H: Human organic cation transporter 3 mediates the transport of antiarrhythmic drugs. Eur J Pharmacol 2004;499:45-51.

11 Li S, Chen Y, Zhang S, More SS, Huang X, Giacomini KM: Role of organic cation transporter 1, OCT1 in the pharmacokinetics and toxicity of cis-diammine(pyridine)chloroplatinum(II) and oxaliplatin in mice. Pharm Res 2011;28:610-625.

12 Busch AE, Quester S, Ulzheimer JC, Waldegger S, Gorboulev V, Arndt P, Lang F, Koepsell H: Electrogenic properties and substrate specificity of the polyspecific rat cation transporter rOCT1. J Biol Chem 1996;271:32599-32604.

13 Kekuda R, Prasad PD, Wu X, Wang H, Fei YJ, Leibach FH, Ganapathy V: Cloning and functional characterization of a potential-sensitive, polyspecific organic cation transporter (OCT3) most abundantly expressed in placenta. J Biol Chem 1998;273:15971-15979.

14 Koepsell H, Schmitt BM, Gorboulev V: Organic cation transporters. Rev Physiol Biochem Pharmacol 2003;150:36-90.

15 Gorboulev V, Ulzheimer JC, Akhoundova A, Ulzheimer-Teuber I, Karbach U, Quester S, Baumann C, Lang F, Busch AE, Koepsell H: Cloning and characterization of two human polyspecific organic cation transporters. DNA Cell Biol 1997;16:871-881. 


\section{Cellular Physiology Cell Physiol Biochem 2012:30:269-281 \begin{tabular}{ll|l} 
and BiOChemistry & $\begin{array}{l}\text { DOI: 10.1159/000339063 } \\
\text { Published online: June 19, } 2012\end{array}$ & $\begin{array}{l}\text { C 2012 S. Karger AG, Basel } \\
\text { www.karger.com/cpb }\end{array}$ \\
$\begin{array}{l}\text { Guckel/Ciarimboli/Pavenstädt/Schlatter: Regulation of Organic Cation Transport in } \\
\text { Isolated Mouse Proximal Tubules }\end{array}$
\end{tabular} Isolated Mouse Proximal Tubules}

16 Gründemann D, Gorboulev V, Gambaryan S, Veyhl M, Koepsell H: Drug excretion mediated by a new prototype of polyspecific transporter. Nature 1994;372:549-552.

17 Mehrens T, Lelleck S, Cetinkaya I, Knollmann M, Hohage H, Gorboulev V, Boknik P, Koepsell H, Schlatter E: The affinity of the organic cation transporter rOCT1 is increased by protein kinase C-dependent phosphorylation. J Am Soc Nephrol 2000;11:1216-1224.

18 Koepsell H, Gorboulev V, Arndt P: Molecular pharmacology of organic cation transporters in kidney. J Membr Biol 1999;167:103-117.

19 Koepsell H, Busch A, Gorboulev V, Arndt P: Structure and Function of Renal Organic Cation Transporters. News Physiol Sci 1998;13:11-16.

20 Holle SK, Ciarimboli G, Edemir B, Neugebauer U, Pavenstädt H, Schlatter E: Properties and regulation of organic cation transport in freshly isolated mouse proximal tubules analyzed with a fluorescence readerbased method. Pflugers Arch 2011;462:359-369.

21 Cetinkaya I, Ciarimboli G, Yalcinkaya G, Mehrens T, Velic A, Hirsch JR, Gorboulev V, Koepsell H, Schlatter E: Regulation of human organic cation transporter hOCT2 by PKA, PI3K, and calmodulin-dependent kinases. Am J Physiol Renal Physiol 2003;284:F293-F302.

22 Pietig G, Mehrens T, Hirsch JR, Cetinkaya I, Piechota H, Schlatter E: Properties and regulation of organic cation transport in freshly isolated human proximal tubules. J Biol Chem 2001;276:33741-33746.

23 Wilde S, Schlatter E, Koepsell H, Edemir B, Reuter S, Pavenstädt H, Neugebauer U, Schröter R, Brast S, Ciarimboli G: Calmodulin-associated post-translational regulation of rat organic cation transporter 2 in the kidney is gender dependent. Cell Mol Life Sci 2009;66:1729-1740.

24 Ciarimboli G, Koepsell H, Iordanova M, Gorboulev V, Durner B, Lang D, Edemir B, Schröter R, Van LT, Schlatter E: Individual PKC-phosphorylation sites in organic cation transporter 1 determine substrate selectivity and transport regulation. J Am Soc Nephrol 2005;16:1562-1570.

25 Hohage H, Morth DM, Querl IU, Greven J: Regulation by protein kinase C of the contraluminal transport system for organic cations in rabbit kidney S2 proximal tubules. J Pharmacol Exp Ther 1994;268:897-901.

26 Urakami Y, Okuda M, Saito H, Inui K: Hormonal regulation of organic cation transporter OCT2 expression in rat kidney. FEBS Lett 2000;473:173-176.

27 Volk C, Gorboulev V, Budiman T, Nagel G, Koepsell H: Different affinities of inhibitors to the outwardly and inwardly directed substrate binding site of organic cation transporter 2. Mol Pharmacol 2003;64:10371047.

28 Biermann J, Lang D, Gorboulev V, Koepsell H, Sindic A, Schröter R, Zvirbliene A, Pavenstädt H, Schlatter E, Ciarimboli G: Characterization of regulatory mechanisms and states of human organic cation transporter 2. Am J Physiol Cell Physiol 2006;290:C1521-C1531.

29 Ciarimboli G, Struwe K, Arndt P, Gorboulev V, Koepsell H, Schlatter E, Hirsch JR: Regulation of the human organic cation transporter hOCT1. J Cell Physiol 2004;201:420-428.

30 Martel F, Keating E, Calhau C, Gründemann D, Schömig E, Azevedo I: Regulation of human extraneuronal monoamine transporter (hEMT) expressed in HEK293 cells by intracellular second messenger systems. Naunyn Schmiedebergs Arch Pharmacol 2001;364:487-495.

31 Brown D, Paunescu TG, Breton S, Marshansky V: Regulation of the V-ATPase in kidney epithelial cells: dual role in acid-base homeostasis and vesicle trafficking. J Exp Biol 2009;212:1762-1772.

32 Wagner CA, Finberg KE, Breton S, Marshansky V, Brown D, Geibel JP: Renal vacuolar H+-ATPase. Physiol Rev 2004;84:1263-1314.

33 Cheung PY, Lai WP, Lau HY, Lo SC, Wong MS: Acute and chronic effect of dietary phosphorus restriction on protein expression in young rat renal proximal tubules. Proteomics 2002;2:1211-1219.

34 Murer H, Forster I, Hilfiker H, Pfister M, Kaissling B, Lotscher M, Biber J: Cellular/molecular control of renal $\mathrm{Na}$ /Pi-cotransport. Kidney Int Suppl 1998;65:S2-10.

35 Murer H, Lotscher M, Kaissling B, Biber J: Molecular mechanisms in the regulation of renal proximal tubular Na/phosphate cotransport. Kidney Blood Press Res 1996;19:151-154.

36 Ahmad A, Khundmiri SJ, Pribble F, Merchant ML, Ameen M, Klein JB, Levi M, Lederer ED: Role of vacuolar ATPase in the trafficking of renal type IIa sodium-phosphate cotransporter. Cell Physiol Biochem 2011;27:703-714. 